\title{
МЕГАПРОЕКТ КАК ИНСТИТУЦИОНАЛЬНАЯ ОСНОВА СТАНОВЛЕНИЯ ГЕОЭКОНОМИЧЕСКИХ РЕГИОНОВ
}

\begin{abstract}
АНнотАция. Масштабные инфраструктурные проекты (мегапроекты) выступают эффективной основой устойчивого развития экономики страны и ее регионов. Реализация мегапроектов, благодаря своим масштабам, значительно меняет хозяйственный ландшафт обширных территорий, формируя качественно иную институциональную среду и способствуя их более эффективному глобальному геоэкономическому позиционированию. Возникновение геоэкономических регионов (внутренних, трансграничных, международных) чаще всего связано с формированием масштабных транспортно-коммуникационных и ресурспользовательских инфраструктур - результатов реализации соответствующих мегапроектов. Необходимость мегапроектов обусловлена обострением глобальной конкуренции и потребностью в обеспечении устойчивого и безопасного развития регионов. Мегапроекты носят межотраслевой характер, охватывают обширные территории и способствуют становлению в регионе сбалансированного хозяйственного комплекса. Разработка и реализация мегапроектов в конкретном геоэкономическом направлении способствует формированию соответствующих территориальных структур - геоэкономических регионов и выступает эффективным инструментом ускорения темпов регионального экономического развития.

КЛючЕВЫЕ СЛОВА. Геоэкономика; геоэкономический регион; региональная экономика; мегапроект.

ИНФОРМАЦИЯ О СТАТЬЕ. Дата поступления 13 апреля 2017 г.; дата принятия к печати 28 апреля 2017 г.; дата онлайн-размещения 19 июня 2017 г.
\end{abstract}

M. L. Bagaynikov Baikal State University, Irkutsk, Russian Federation

\section{MEGAPROJECT AS AN INSTITUTIONAL BASIS OF ESTABLISHING GEO-ECONOMIC REGIONS}

\begin{abstract}
Large-scale infrastructural projects (megaprojects) serve as an effective basis for sustainable development of the country's economy and its regions. Implementation of megaprojects, due to their scale, significantly changes the economic landscape of vast territories while forming a qualitatively different institutional environment and contributing to their more effective global geo-economic positioning. Emergence of geo-economic regions (domestic, cross-border, international ones) is most often associated with developing large-scale transport-communication and resource-use infrastructures - the results of implementing the relevant megaprojects. The necessity for megaprojects is due to aggravation of the global competition and the need to ensure sustainable and safe development of the regions. Megaprojects are of an inter-sectoral nature, they cover vast territories and contribute to establishing a balanced economic complex in the region. Development and implementation of megaprojects in a specific geo-economic direction contribute to formation of appropriate territorial structures - geo-economic regions and serves as an effective tool to accelerate the pace of regional economic development.

KEYWORDS. Geo-economics; geo economic region; regional economy; megaproject.

ARTICLE INFO. Received April 13, 2017; accepted April 28, 2017; available online June 19, 2017.
\end{abstract}

(C) М. Л. Багайников, 2017

\section{Baikal Research Journal}


Экономически развитые государства имеют зоны национальных интересов, локализованные в виде геоэкономических регионов. При этом формирование таких зон осуществляется, как правило, путем создания сухопутных и морских коммуникаций, каналов и маршрутов передачи энергии. В этом смысле формирование и функционирование геоэкономических регионов в полной мере вписывается в существующую теорию морского и сухопутного могущества государств - теллурократии и талассократии, что подразумевает наличие стран моря и суши. Однако наиболее развитые страны сочетают в себе обе характеристики, развиваясь одновременно и как «страна моря», и как «страна суши». Это обуславливает наличие соответствующих зон национальных интересов, то есть геоэкономических регионов моря и суши, и чем сильнее государство, тем больше таких зон и тем они обширнее.

Представляется, что геоэкономический регион имеет существенные отличия от существующих сегодня регионов страны, очерченных административными границами, которые в современных условиях уже не отвечают критериям әффективности социально-экономического развития территорий. Эти различия помимо внешних атрибутов имеют различия внутреннего, содержательного характера. Прежде всего, геоэкономический регион это территориальная структура, формируемая государством (в условиях слабого государства, формирование геоэкономических регионов проходит стихийно, либо режиссируются извне) как система управления процессами хозяйственного освоения и обустройства собственной территории, а также суверенных территорий третьих стран, вовлекаемых в процессы геоэкономического районирования, точнее в процессы создания геоэкономических транспортно-энергетических и ресурсопользовательских инфраструктур [1].

Именно этот аспект имеет сегодня наибольшее значение, поскольку необходимость структурных преобразований в хозяйстве России по-прежнему сохраняет свою актуальность. Особенно остро данный вопрос стоит во многих сибирских и дальневосточных регионах, чьи хозяйственные комплексы до сих пор развиваются по траектории, заложенной еще в 1990-е гг., когда Россия видела себя на геоэкономической карте мира, как «энергетическую супердержаву». Это создало предпосылки для укоренения в регионах ресурсоориентированного пути развития хозяйств. Мерой, обеспечивающей постепенный переход таких регионов (ресурсного типа) на путь экономически сбалансированного комплексного развития хозяйства, выступает формирование в них единых, с точки зрения национального хозяйства, транспортно-энергетических и ресурсопользовательских региональных геоэкономических инфраструктур, представляющих собой компоненты масштабных инфраструктурных проектов уровня (мегапроектов).

Формирование таких инфраструктур (для каждого региона свои) попутно способствует более «тонкой» настройке региональных институтов управления в соответствии со сложившимися в регионах поведенческими стереотипами, особенностями менталитета и традициями регионального управления. При этом процесс формирования таких институтов управления подстраивается под особенности институциональной среды, сложившейся и развивающейся в конкретном геоэкономическом направлении.

Однако основой устойчивого социально-экономического развития регионов являются региональные хозяйственные комплексы, использующие природно-ресурсный потенциал территории, и развивающиеся в рамках национальной стратегии в определенном геоэкономическом направлении. Часто в качестве локомотива территориального экономического развития выступают масштабные инфраструктурные проекты, часто именуемые как мегапроекты. Такими мегапроектами национального масштаба стали, в частности, план ГОЭРЛО, в результате реализации которого

\section{Baikal Research Journal}

электронный научный журнал Байкальского государственного университета 
возникла сетка экономических районов СССР; космическая программа, индустриализация; интенсификация сельского хозяйства; атомная энергетика и т. п.

К числу наиболее значимых по своему масштабу территориальных мегапроектов настоящего времени можно отнести «Комплексное развитие Нижнего Приангарья», «Комплексное развитие Забайкалья», «Комплексное развитие Южной Якутии». В настоящее время доминируют мегапроекты, связанные с развитием топливно-энергетического комплекса (Ямал, Сахалин, Восточно-Сибирский нефтегазовый комплекси металлургии («Урал промышленный - Урал полярный») [2].

Учеными Института экономики и организации промышленного производства CO PAH в качестве площадки для реализации масштабной программы устойчивого развития макрорегиона Сибирь (в границах Сибирского федерального округа (СФО)), выделен мегапроект «Юго-Восток», включающий в себя территории рублик Тыва и Бурятия, а также Иркутской области и Забайкальского края. Кроме того, выделены мегапроекты по комплексному развитию и других территорий СФО, в частности, «Юго-Запад» и «Север - Арктическая зона» [3]. Каждый из предложенных проектов имеет свои цели и задачи, свой организационно-экономический механизм реализации. Объединяет же их необходимость в создании специального института по координации государственно-частного взаимодействия на всех этапах их разработки и реализации.

Большое значение имеет также трансграничный аспект реализации мегапроектов, который долгое время игнорировался при решении задач пространственной организации национального и регионального хозяйства. Очевидно, что формирование и функционирование внутренних геоэкономических регионов, не смотря на некоторое изменение вектора развития мирового хозяйства от «абсолютного» глобализма к экономическому «национализму» и «континентализму», будет иметь выраженный экстравертный характер. Способствует тому и усиливающееся геокультурное взаимодействие, которое в отличие от экономической сферы не утратило потенциала к усилению конвергенции. Т. И. Герасименко и М. Г. Лапаева отмечают смещение и «размытие» границ геопространства, подсистемой (слоем) которого является этнокультурное пространство видоизменяющееся, в том числе в результате усиления трансграничного взаимодействия [4]. Речь в данном случае идет о взаимопроникновении культур и цивилизаций, влекущих за собой расширение взаимодействия субъектов хозяйствования. Политические границы стран в большом числе случаев «рассекли» некогда единые в этнокультурном и хозяйственном плане пространства, в связи, с чем процессы усиления трансграничного взаимодействия последнего времени зачастую носят объективный, можно даже сказать, неизбежный характер. Таким образом, мегапроекты могут стать также фактором усиления социально-культурного взаимодействия между населением сопредельных стран, что может породить значимый геокультурный эффект, положительно влияющий на становление геоэкономических регионов.

Если углубиться в историю вопроса, то станет ясно, что мегапроекты зачастую способствовали формированию и становлению разного рода геопространственных структур. Например, формирование тесных торговых и культурных связей между городами Северной Европы XII в., привело к формированию достаточно устойчивого территориального образования - Ганзейского торгового союза, участники которого взаимодействовали в едином правовом и экономическом пространстве, что обеспечивало устойчивый экономический рост и, как следствие, рост политического, экономического и даже военного влияния в регионе.

Великие географические открытия, колонизация и становление морских торговых маршрутов привели к тому, что экономическое, культурное и политическое влияние западноевропейской цивилизации обрело планетарные масштабы. В ре-

\section{Baikal Research Journal}

электронный научный журнал Байкальского государственного университета 
зультате появились гигантские зоны влияния (геостратегические регионы) европейских держав, позволившие осуществлять переток экономических ресурсов из периферии глобального пространства в ядро сформированной европоцентричной «мир-системы». «Развитие морского флота Европы, - отмечают Г. В. Осипов и др., - стало необходимым условием для великих географических открытий, первой волны глобализации и становления современного Запада» [5, с. 15].

Внимания заслуживает американский опыт реализации мегапроектов, в частности, проект развития долины реки Теннесси (Администрация реки Теннесси TVA) и Региональная комиссия гор Аппалачей (ARC). Стратегическими целями упомянутых проектов стали не только обеспечение устойчивого экономического развития соответствующих территорий, но и защита окружающей среды, технологические инновации, улучшение бизнес-среды, повышение энергоэффективности и рационализация ресурсопользования. Для достижения поставленных целей была проведена коренная модернизация всей производственной и социальной инфраструктуры территорий и созданы специальные институты управления развитием проектов ${ }^{1}$.

Показателен и отечественный опыт реализации мегапроектов. Геостратегические интересы России XIX в. в Азии обусловили строительство Транссиба одного из крупнейших в отечественной истории инфраструктурных проектов. С его помощью решались задачи хозяйственного освоения Сибири и сглаживания имевших место в регионе военно-политических проблем. Более того проект пространственно локализовал «регион Транссиба» (который в контексте исторического периода следует идентифицировать как геоэкономический регион), ставшего объектом целенаправленного управления со стороны государства, что привело к существенному росту производительных сил Сибири. Кроме того строительство Транссиба имело огромное политическое значение, позволившее окончательно закрепить суверенитет над азиатскими территориями России.

Локомотивом восстановления и модернизации народного хозяйства страны в послевоенный период стали мегапроекты в ракетно-космической области и создание нефтегазового комплекса Сибири. И сегодня в качестве альтернативного направления развития экономики, мегапроектам уделяется достаточно большое внимание, поскольку они «оптимальным образом позволят разрешить критические социальные, экономические и политические проблемы, отодвинуть геополитические риски и угрозы» [5, с. 5]. Отсюда следует, что успешная реализация мегапроектов станут мощными факторами инновационного развития экономики, повлияют на трансформацию мирохозяйственных связей России, и будут способствовать формированию новых центров мировой торговли [6].

Накопленный мировой и отечественный опыт свидетельствует, что геоэкономические регионы, как правило, возникают в ареале реализации различных проектов (чаще мегапроектов), сегментированных монопроектами - отдельными проектами «определенного типа и масштаба, имеющими цель и задачи, ограничения по ресурсам, срокам, качеству и другим характеристикам» [7, с. 9]. Такое преставление геоэкономического региона требует переосмысления подходов к управлению территориальными социально-экономическими системами путем максимально широкого использования программно-проектного подхода, свойственного для мегапроекта.

Мегапроект, как правило, состоит из нескольких взаимосвязанных проектов, имеющих общую цель и ресурсы, высокую стоимость реализации и рассчитанный на длительный период. Чаще всего это объекты инфраструктуры, обеспечи-

1 Tennessee Valley Authority. Key Topic — 2011 Performance. URL: http://tva.gov/news/ keytopics/2012_perf.htm.

\section{Baikal Research Journal}

электронный научный журнал Байкальского государственного университета 
вающие новые качественные подходы к развитию территорий, а эксплуатация результатов мегапроекта существенным образом влияет на социально-экономическое развитие не только конкретного региона, где осуществлялся проект, но и страны в целом [7]. То есть мегапроект представляет собой системный комплекс взаимосвязанных проектов, как правило, межотраслевого уровня, реализуемый на большой территории и имеющий общегосударственное значение.

Посредством реализации мегапроектов некоторыми странами, так называемой глобальной периферии (по Ф. Броделю), прежде всего Китаем, проводится политика экономического противодействия давлению «ядру мир-системы». То есть имеет место реализация классической стратегии «глобальной периферии» догнать и перегнать «центр». При этом геоэкономический центр стремится к максимальной либерализации системы мирохозяйственных связей, выраженной свободным перемещением рабочей силы, ресурсов и капитала, а также свободой торговли, с целью экономического захвата «периферии», тогда как периферийные экономические системы напротив, проводят протекционистскую политику, развивают внутреннее производство и создают региональные экономические и политические союзы и альянсы [8]. Важную роль при этом играют национальные мегапроекты, многие из которых уже имеют статус транснациональных.

Похожие проблемы свойственны и экономическому пространству России, где также существует доминирующий экономический «центр» и чрезвычайно дифференцированная по уровню развития, экономическая периферия. Учитывая же официальную смену идеологии и «поворот $к$ регионам», предусматривающей реализацию национальной стратегии пространственного развития и согласно которой в регионах «могут или должны сконцентрироваться ограниченные ресурсы бюджета для решения важнейших инфраструктурных, социальных, геостратегических задач, где должны и могут быть созданы приоритетные институциональные режимы» [9, с. 10]. Одной из таких институциональных основ в полной мере может стать мегапроект, в полной мере учитывающий потребности региона и реализующийся в рамках национальной стратегии пространственного развития.

В условиях сохранения тенденции либерализации международных экономических отношений, сопровождаемых усилением взаимосвязи между политикой и экономикой, организация и продвижение мегапроектов общегосударственного значения, «предполагает геополитические, макроэкономические, социально-экономические цели устойчивого развития и обеспечения национальной безопасности РФ»[2, с. 15].

В настоящее время можно выделить следующие специфические особенности мегапроекта как объекта стратегического планирования:

- зависимость содержания от геополитических факторов и ситуаций;

- неопределенность условий внешней и институциональной среды;

- наличие организационно-экономических и инновационных рисков проектов;

- состязательность интересов отраслей и регионов за государственную поддержку и привлечение проектов на территорию;

- высокая дифференциация инфраструктурной обеспеченности регионов [2].

Таким образом, мегапроект потенциально может играть роль важного системообразующего института регионального развития, способствующего формированию межотраслевых хозяйственных комплексов на внушительной территории (мегапроекты как правило не ограничены рамками административно-территориальных границ и охватывают сразу несколько субъектов РФ).

Мегапроекты развиваются либо в рамках геоэкономического региона, либо выходят за его границы, способствуя трансформации и модернизации террито-

\section{Baikal Research Journal}

электронный научный журнал Байкальского государственного университета 
риальной социокультурной и производственной инфраструктуры. Кроме того, мегапроект может охватывать сразу несколько геоэкономических регионов, а в определенных случаях и территории сопредельных государств, оказавшихся в зоне экономического воздействия проекта. Следует отметить, что мегапроектами могут считаться «только те проекты, которые меняют экономический ландшафт затрагиваемого осуществлением планируемых преобразований хозяйственного пространства, причем в заданном стратегическом направлении» [10, с. 15].

Мегапроекты способствуют укреплению межотраслевых связей и, тем самым, формированию единого национального и регионального хозяйственного комплекса, что усиливает конкурентные позиции экономики страны на мировом рынке и развивает трансграничное сотрудничество. Последнее делает возможным включение в орбиту экономических интересов государства хозяйственных комплексов и экономических агентов, находящихся на сопредельной территории. Также важным аспектом реализации мегапроектов, особенно для развития регионов ресурсного типа, является ослабление негативного эффекта периферийности территорий. Если исходить из концепции центро-периферийного пространственного развития (Дж. Фридман, Ф. Бродель, Э. Валлерстайн), согласно которой экономические центры разного уровня способствуют одностороннему передвижению ресурсов (финансовых, человеческих и природных) из периферии к ядру, то мегапроекты могут выступать в качестве рестриктора, препятствующего их неэффективному, одностороннему «перетоку».

Вместе с тем, учитывая сложившуюся за последние полтора десятка лет патерналистскую практику взаимоотношений между центром и регионами, возникает вопрос заинтересованности первого в реализации такого сценария, а именно в частичной смене направления «перетока» ресурсов. Российский опыт реализации крупных межотраслевых проектов базирующийся «на вертикальных организационных схемах взаимодействия субъектов хозяйствования - соглашения между компаниями и государством, как правило, опосредованы решением властных структур и имеют рекомендательный характер вместо юридически оформленных контрактов», требует скорейшего пересмотра [2, с. 17]. Более того, организационно-функциональная структура органов государственной власти не предусматривает наличия специального института, осуществляющего планирование взаимодействия мегапроектов и бизнеса на этапе их разработки.

Мировой опыт в сфере реализации мегапроектов показывает, что ключевую координирующую функцию в вопросах взаимодействия власти и бизнеса выполняют специальные государственные институты, выполняющие целеполагание (определение целей и задач проекта) и возлагающие на себя организационные вопросы (отбор участников мегапроектов). Изучая процессы формирования и становления внутренних геоэкономических регионов через реализацию мегапроектов, становится более ощутимым представление о регионах, как о программно-проектных территориях проблемного типа, поскольку сам мегапроект полностью вписывается в стратегию развития национального хозяйства, являя собой его структурный, решающий задачи общегосударственного значения посредством регионов, компонент.

К числу мегапроектов, реализация которых позволит модернизировать инфраструктуру наиболее проблемных в экономическом плане территорий азиатской России, а также будет способствовать более глубокой интеграции национального хозяйства и хозяйств регионов в глобальную воспроизводственную систему можно отнести следующие:

1. Развитие Северный морского пути (СМП), как альтернативного трансконтинентального транспортного маршрута, позволяющего участвовать в междуна-

\section{Baikal Research Journal}

электронный научный журнал Байкальского государственного университета 
родной конкуренции в сфере грузоперевозок, а также вовлечение углеводородных районов Арктического побережья. Именно возможность использовать СМП вызывает все больший интерес, поскольку является кратчайшим путем между портами Европы, России, дальнего востока и Юго-Восточной Азии (например, расстояние проходимое судами от Мурманск до Йокогамы по традиционному маршруту через Суэцкий канал, составляет 12840 миль, тогда как СМП - 5770) [11].

2. Энергомост «Сибирь - Урал - Центр», имеющий большое значение в контексте развития национальной и региональных энергетических инфраструктур и повышения энергетической безопасности, а также реализации ресурсного потенциала азиатских территорий России.

3. Международный энергетический проект «Энергетическое суперкольцо», которое в перспективе должен объединить в единую систему энергосистемы России, Монголии, Китая, Республики Корея и Японии, капитализировав тем самым, ресурсный потенциал сразу нескольких российских регионов, а также позволит эффективнее интегрироваться в глобальные воспроизводственные системы.

4. Трансконтинентальная транспортная магистраль между Азией и Америкой «Якутск - Магадан - Анадырь - Аляска», предусматривающая строительство подводного тоннеля между двумя континентами. Реализация этих мегапроектов способна существенно трансформировать инфраструктуру причастных к ним территорий, а также более широко использовать их природно-ресурсный потенциал. Кроме того активизируется формирование соответствующих территориальных структур - внутренних и трансграничных геоэкономических регионов, поскольку каждый отдельно взятый мегапроект реализуется в рамках конкретного геоэкономического направления развития экономики страны. Также внимания заслуживает проект создания трансконтинентального транспортного коридора, соединяющего Европу и Азию, а в перспективе и Северную Америку через Берингов пролив, на основе модернизированной Транссибирской магистрали, дополненного меридиональными хозяйственными системами, например, «трансазийскийм коридором развития» от Ямала до Индии, через Урал - Казахстан - Иран и др. [5].

Реализация мегапроектов на периферии географического и экономического пространства страны в современных условиях позволит эффективнее осуществить инновационную модернизацию экономики регионов, усовершенствовать их институциональную инфраструктуру, а главное обеспечить повышение уровня жизни населения, препятствовать их оттоку в другие регионы и способствовать сохранению его этнокультурной составляющей. Кроме того, реализация мегапроекта на периферии экономического пространства страны означает если не первичное хозяйственное освоение ресурсной территории, то перезапуск всего хозяйственного механизма, после его остановки в кризисные годы. Реализация мегапроектов является свидетельством появления новых экономических возможностей для крупномасштабного экономического развития (в том числе регионального) и фактором его интенсификации. Это особенно важно в современных геополитических условиях, когда «внимание к таким территориям усиливается в связи с новой геополитической реальностью, когда обостряются международные противоречия, связанные, в том числе и с неравномерностью глобального расселения и распределения природных ресурсов" [12, с. 534].

Использование мегапроекта как институциональной платформы регионального развития требует переосмысления подходов к управлению территориальными социально-экономическими системами путем максимально широкого использования программно-проектного подхода при реализации мегапроектов как факторов становления геоэкономических регионов.

\section{Baikal Research Journal}




\section{Список использованной литературы}

1. Рогов В. Ю. Основы формирования геоэкономических регионов современной России / В. Ю. Рогов. - Иркутск : Изд-во БГУЭП, 2002. - 200 с.

2. Пляскина Н. И. Стратегическое планирование межотраслевых ресурсных мегапроектов: методология и инструментарий / Н. И. Пляскина, В. Н. Харитонова // Проблемы прогнозирования. - 2013. - Т. 24, № 2. - С. 15-27.

3. Черников А. П. Сибирь: проблемы развития / А. П. Черников // Известия Иркутской государственной экономической академии. - 2012. - № 4 (84). - С. 58-60.

4. Герасименко Т. И. Формирование трансграничных регионов как пространственно-временной результат трансграничного взаимодействия / Т. И. Герасименко, М. Г. Лапаева // Вестник Оренбургского государственного университета. - 2012. - № 2 (138). C. $298-302$.

5. Осипов Г. В. Интегральная евразийская инфраструктурная система как приоритет национального развития страны / Г. В. Осипов, В. А. Садовничий, В. И. Якунин. - М. : Ин-т соц.-полит. исслед. РАН, 2013. - 62 с.

6. Вижина И. А. Проблемы государственно-частного партнерства в стратегических проектах Севера / И. А. Вижина, А. А. Кин, В. Н. Харитонова // Регион: экономика и социология. -2011 . - № 4. - С. $152-175$.

7. Юрьева Т. В. Проектный подход как инструмент реализации стратегических целей / Т. В. Юрьева // Экономические науки. - 2014. - № 11 (120). - С. 7-10.

8. Метелева Е. Р. Стратегическое управление развитием экономических систем в условиях глобализации / Е. Р. Метелева // Известия Иркутской государственной экономической академии. - 2016. - T. 26, № 3. - C. 426-433. - DOI: 10.17150/19933541.2016.26(3).426-433.

9. Минакир П. А. Институциональные отображения пространственного развития / П. А. Минакир // Пространственная экономика. - 2016. - № 4. - С. 7-12.

10. Волошина А. Ю. Реализация мегапроектов как фактор ускорения регионального развития / А. Ю. Волошина // Вестник Волгоградского государственного университета. Сep. 3, Экономика. Экология. - 2010. - № 2. - С. 15-20.

11. Краснопольский Б. Х. Национальная и глобальная инфраструктура арктической зоны ATP: новые вызовы / Б. Х. Краснопольский // Пространственная экономика. 2015. - № 2. - C. 165-179.

12. Татаркин А. И. Приоритеты подготовки и реализации стратегических мегапроектов вовлечения новых углеводородных районов Арктического побережья / А. И. Татаркин, М. Б. Петров // Вестник Мурманского государственного технического университета. 2015. - T. 18, № 3. - C. 533-536.

\section{References}

1. Rogov V. Yu. Osnovy formirovaniya geoekonomicheskikh regionov sovremennoi Rossii [Basics of forming geo-economic regions of modern RussiaIrkutsk, Baikal State University of Economics and Law Publ., 2002. 200 p.

2. Plyaskina N. I., Kharitonova V. N. Strategic planning of cross-sectoral resource megaprojects: Methodology and instruments. Problemy prognozirovaniya = Studies on Russian Economic Development, 2013, vol. 24, no. 2, pp. 15-27. (In Russian).

3. Chernikov A. P. Siberia: problems of development. Izvestiya Irkutskoi gosudarstvennoi ekonomicheskoi akademii = Bulletin of Irkutsk State Economics Academy, 2012, no. 4 (84), pp. 58-60. (In Russian).

4. Gerasimenko T. I., Lapayeva M. G. Formation of trans-border regions as a spatial temporary result of trans-border interaction. Vestnik Orenburgskogo gosudarstvennogo universiteta $=$ Bulletin of Orenburg State University, 2012, no. 2 (138), pp. 298-302. (In Russian).

5. Osipov G. V., Sadovnichy V. A., Yakunin V. I. Integral'naya evraziiskaya infrastrukturnaya sistema kak prioritet natsional'nogo razvitiya strany [Integral Eurasian infrastructural system as a priority of country's national development]. Moscow, Institution of the Russian Academy of Sciences, Institute of Socio-Political Research RAS Publ., 2013. 62 p.

6. Vizhina I. A., Kin A. A., Kharitonova V. N. Problems of public-private partnership in implementing strategic projects of the North. Region: ekonomika $i$ sotsiologiya = Region: Economics and Sociology, 2011, no. 4, pp. 152-752. (In Russian).

\section{Baikal Research Journal}


7. Yuryeva T. V. Project approach as an instrument of achieving strategic goals. Ekonomicheskie nauki = Economic Sciences, 2014, no. 11 (120), pp. 7-10. (In Russian).

8. Meteleva E. R. Strategic management of economic system development under globalization conditions. Izvestiya Irkutskoi gosudarstvennoi ekonomi-cheskoi akademii = Bulletin of Irkutsk State Economics Academy, 2016, vol. 26, no. 3, pp. 426-433. DOI: 10.17150/19933541.2016.26(3).426-433. (In Russian).

9. Minakir P. A. Institutional reflection of spatial development. Prostranstvennaya ekonomika = Spatial Economics, 2016, no. 4, pp. 7-12. (In Russian).

10. Voloshina A. Yu. Implementation of mega-projects as a factor of accelerating regional development. Vestnik Volgogradskogo gosudarstvennogo universiteta. Seriya 3, Ekonomika. Ekologiya = Scientific Journal of Volgograd State University. Economy. Ecology, 2010, no. 2, pp. 15-20. (In Russian).

11. Krasnopolsky B. Kh. National and global infrastructure of the Arctic Zone of the APR: new challenges. Prostranstvennaya ekonomika = Spatial Economics, 2015, no. 2, pp. 165-179. (In Russian).

12. Tatarkin A. I., Petrov M. B. Priorities for preparation and implementation of strategic mega-projects involving new hydrocarbon areas of the Arctic coast. Murmanskogo gosudarstvennogo tekhnicheskogo universiteta = Bulletin of Murmansk State Technical University, 2015, vol. 18, no. 3, pp. 533-536. (In Russian).

\section{Информация об авторе}

Багайников Михаил Логинович - кандидат экономических наук, доцент, докторант, кафедра бухгалтерского учета, анализа, статистики и аудита, Байкальский государственный университет, 664003, г. Иркутск, ул. Ленина, 11, e-mail: koterik@mail.ru.

\section{Author}

Mikhail L. Bagaynikov - PhD in Economics, Associate Professor, Doctoral Student, Chair of Accounting, Analysis, Statistics and Audit, Baikal State University, 11 Lenin St., 664003, Irkutsk, Russian Federation; e-mail: koterik@mail.ru.

\section{Библиографическое описание статьи}

Багайников М. Л. Мегапроект как институциональная основа становления геоэкономических регионов / М. Л. Багайников // Baikal Research Journal. — 2017. — T. 8, № 2. DOI: $10.17150 / 2411-6262.2017 .8(2) .21$.

\section{Reference to article}

Bagaynikov M. L. Megaproject as an institutional basis of establishing geo-economic regions. Baikal Research Journal, 2017, vol. 8, no. 2. DOI: 10.17150/2411-6262.2017.8(2).21. (In Russian).

\section{Baikal Research Journal}

